TP Periodica Polytechnica

Mechanical Engineering

60(2), pp. 89-95, 2016

DOI: 10.3311/PPme. 8571

Creative Commons Attribution (i)

RESEARCH ARTICLE

\section{Effect of the Fins Length for the Passive Cooling of the Photovoltaic Panels}

\author{
Taieb Nehari ${ }^{1 *}$, Mohamed Benlakam ${ }^{2}$, Driss Nehari ${ }^{2}$
}

Received 16 September 2015; accepted after revision 02 February 2016

\begin{abstract}
A two-dimensional (2D) numerical model was used to simulate the use of a phase change material linked to a PV system to control the temperature rise of the PV cells. The predicted temperatures using the $2 D$ model have been compared with experimental and numerical data of the literature and a good agreement was obtained for both the isotherm contours and time evolution of the temperature.

An extended surface (fins) has been used in order to improve conductive heat transfer and to reinforce the thermal homogeneity. Concerning the inner fins included on the PV panel (Front), the obtained results show that these fins reduce significantly the temperature. Furthermore, the configurations of $L=25,30$ and $35 \mathrm{~mm}$ allow better cooling of the PV panel. On the other hand, the back inner fin used reduces dramatically the performance of the PV/PCM system for cooling the panel.
\end{abstract}

\section{Keywords}

PCM, Natural convection, Cooling PV panel

\footnotetext{
${ }^{1}$ Department of Mechanical Engineering, Faculty of Mechanical Engineering, Oran University of Science and Technology, 31000 Oran, Algeria

${ }^{2}$ Department of Mechanical Engineering, Laboratory of Smart Structure, Ain Temouchent University, 46000 Ain Temouchent, Algeria

*Corresponding author, e-mail: nehari1976@gmail.com
}

\section{Introduction}

The photovoltaic (PV) panel absorbs only about $16 \%$ of the incident solar energy that is converted into electricity; the remaining insolation absorbed is transformed into heat [1]. The photovoltaic cell efficiency decreases with increasing temperature [2]. This can typically result in an efficiency drop off of $0.5 \%$ per ${ }^{\circ} \mathrm{C}$ increase in the cell operating temperature. Since, for example, silicon solar cells are characterized at $1000 \mathrm{~W} / \mathrm{m}^{2}$ and $25{ }^{\circ} \mathrm{C}$ as ideal temperature for the cell, maintaining the cell temperature at $25{ }^{\circ} \mathrm{C}$ can retain the rated efficiency of the cell. Cells will also exhibit long-term degradation if the temperature exceeds a certain limit [3].

This problem can be avoided by keeping a uniform temperature across the panel. The use of the extracted thermal energy from cooling can lead to a significant increase in the total conversion efficiency of the receiver. Natural or forced air circulation is a simple and low cost method to remove heat from PV modules, but it is less effective if ambient air temperature is over $20^{\circ} \mathrm{C}$, as it is usual for many months in low latitude countries.

Another, more efficient way is to use a liquid as the coolant of the panel, in order to absorb more heat and to cool the panel more effectively [4]. This is the general philosophy of hybrid photovoltaic-thermal collectors. In such kind of cooling, various investigations have been made producing interesting results.

In the desert, the PV temperature can exceed $40{ }^{\circ} \mathrm{C}$ inducing a power drop in crystalline silicon PV. Increased operating temperature also results in accelerated PV degradation due to cell delamination allowing moisture ingress. The air or water cooling systems are limited by very low heat transfer and large capital as well as maintenance costs [5].

However, a novel method to regulate the rise in PV temperature, phase change materials (PCM), which absorb energy as latent heat at a constant phase transition temperature has been developed and employed recently. The phase change materials undergoing solid-liquid phase transition at or close to $25^{\circ} \mathrm{C}$ can absorb the excess thermal energy during phase change, which otherwise would raise PV operating temperature, and can maintain the $\mathrm{PV}$ operating temperature at or close to $25^{\circ} \mathrm{C}$. 
PCM integrated with PV were modelled with the finite volume method by Huang et al. [6]. The authors have predicted the evolution of the temperature on the front surface of integrated PV/PCM system and the temperature distribution inside the system. The PV/PCM system was experimentally evaluated with different configurations of metallic fins inserted in the PV/ PCM rectangular container to enhance heat transfer by Huang et al. [7]. A small scale 3D model was developed and validated with experimentally validated 2D model for temperature regulation of PV using PCM [7]. Lately, the experimental results of Ahmad [8] show that PCM are an effective way to cool PV and maintain higher power outputs in higher insolation climates.

According to the literature, using extended surface (fins) could improve significantly the heat transfer performance of latent heat storage systems. In this way, Huang and Eames [9] have included the fins into the system in order to improve conductive heat transfer into the bulk of a low conductivity PCM and encourage thermal homogeneity. However, fins also constitute barriers to fluid movement and may thus reduce convective heat transfer in the molten PCM. Nevertheless, it should be interesting to determine the adequate fins length for an optimal configuration PV/PCM system. However, despite all efforts realized for optimizing the performance of solar panels, the actual temperature reaching is still not enough, so that the relentless pursuit of solutions for cooling continues nowadays.

In this sense, the current study aims to investigate numerically the suitable fins length in order to determine the associated power improvement of PV through cooling produced by PCM. The transient conduction and convection heat transfers as well as the Navier-Stokes equations are simultaneously resolved using a finite volume solver.

\section{Numerical modelling}

A schematic 2-D computational domain for all investigated cases is presented in Fig. 1a. The system is comprised of a photovoltaic panel and of a phase change material 'RT25'. Air circulates freely over the PV panel and the back wall of the container of PCM. The PCM is in direct contact with the PV panel and the back wall. The incident energy $I_{T}$ is absorbed and transformed into heat inside the PV-PCM system. In our case, we use the same geometry considered by Huang et al. [6]. Therefore, we use the same boundary and initial conditions of the last authors, which are:

- (i) the initial temperature of the PV $T_{P V}$ is the same as that of the PCM;

- (ii) the heat transfer coefficients from the front and rear surfaces have the fixed values $h_{1}$ and $h_{2}$;

- (iii) for the top and bottom adiabatic boundaries are used for the system.

The thermophysical properties of phase material change "RT25" and Aluminum used in the present investigation are shown in Table 1. As well known, the data of 'RT25' are provided by the manufacturer "RUBITHERM".

(a)

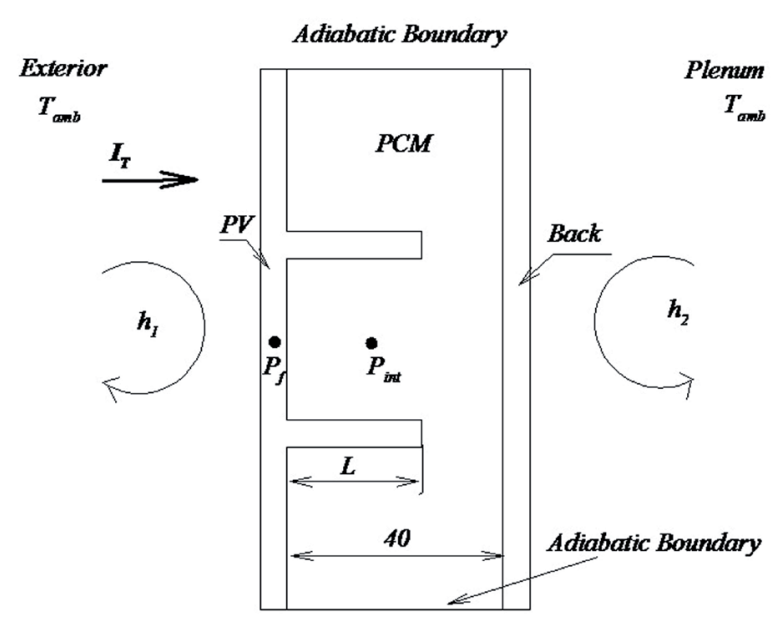

(b)

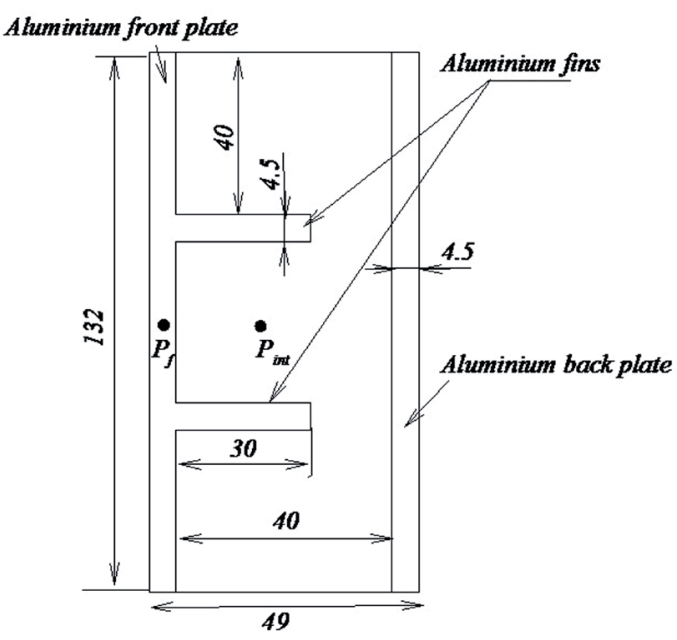

Fig. 1 Schematic diagram of the PV/PCM system with internal fins: a) heat transfer and boundary conditions; b) Geometry of the of the system for the case $\mathrm{L}=30 \mathrm{~mm}$ (dimensions in $\mathrm{mm}$ ).

Table 1 Thermophysical properties of "RT25” [10], Paraffin wax [11] and Aluminium [12].

\begin{tabular}{|c|c|c|c|}
\hline Property & PCM (RT25) & Paraffin wax & Aluminium \\
\hline \multicolumn{4}{|l|}{ Density } \\
\hline Solid, $\mathrm{Kgm}^{-3}$ & 785 & 830 & 2675 \\
\hline Liquid, $\mathrm{Kgm}^{-3}$ & 749 & 830 & Not used \\
\hline \multicolumn{4}{|l|}{ Specific heat capacity Solid, } \\
\hline $\mathrm{Jm}^{-3} \mathrm{~K}^{-1}$ & $1,413,000$ & $1,593,600$ & $2,415,525$ \\
\hline Liquid, $\mathrm{Jm}^{-3} \mathrm{~K}^{-1}$ & $1,797,600$ & $2,705,800$ & Not used \\
\hline \multicolumn{4}{|l|}{ Thermal conductivity } \\
\hline Solid, $\mathrm{Wm}^{-1} \mathrm{~K}^{-1}$ & 0.19 & 0.514 & 211 \\
\hline Liquid, $\mathrm{Wm}^{-1} \mathrm{~K}^{-1}$ & 0.18 & 0.224 & Not used \\
\hline Melting temperature, ${ }^{\circ} \mathrm{C}$ & 26.6 & 32 & Not used \\
\hline Latent heat of fusion, $\mathrm{J}^{\mathrm{kg}} \mathrm{kg}^{-1}$ & 232,000 & 251,000 & Not used \\
\hline
\end{tabular}


Such problem is governed by two-dimensional unsteady energy and Navier-stokes equations. In other hand, the enthalpy-porosity formulation was adopted in solving phase change region in PCM:

The continuity:

$$
\frac{\partial}{\partial x_{i}}\left(\rho u_{i}\right)=0
$$

The momentum:

$$
\frac{\partial}{\partial t}\left(\rho u_{i}\right)+\frac{\partial}{\partial x_{i}}\left(\rho u_{j} u_{i}\right)=\mu \frac{\partial^{2} u_{i}}{\partial x_{i} \partial x_{j}}-\frac{\partial p}{\partial x_{i}}+\rho g_{i}+S_{i}
$$

The energy:

$$
\frac{\partial}{\partial t}(\rho h)+\frac{\partial}{\partial x_{i}}\left(\rho u_{i} h\right)=\frac{\partial}{\partial x_{i}}\left(k \frac{\partial T}{\partial x_{i}}\right)+S_{h}
$$

Where $\rho$ is the density, $k$ denotes the thermal conductivity, $\mu$ is the dynamic viscosity, $\mathrm{S}_{\mathrm{i}}$ and $\mathrm{S}_{\mathrm{h}}$ are the source terms, $u_{i}$ is the velocity component in the $i$-direction, $x_{i}$ is a cartesian coordinate, and $h$ is the specific enthalpy. The sensible enthalpy $\mathrm{h}_{\mathrm{S}}$ is given by:

$$
h_{s}=h_{r e f}+\int_{T_{r e f}}^{T} C_{p} d T
$$

And the total enthalpy, $H$ is defined as

$$
H=h_{s}+\Delta H
$$

Where $\Delta H=\gamma L$ is the enthalpy change due to phase change, $h_{\text {ref }}$ is the reference enthalpy at the reference temperature $T_{\text {ref }}$, $C_{p}$ is the specific heat, $L$ is the specific enthalpy of melting (liquid state) and $\gamma$ is the liquid fraction during the phase change which occur over a range of temperatures $T_{\text {solidus }}<T<T_{\text {Liquidus }}$ defined by the following relations:

- If $\mathrm{T}<T_{\text {solidis }}$ (Solid state)

$$
\gamma=\frac{\Delta H}{L}=0
$$

- If $T_{\text {solidis }}<T<T_{\text {Liquidus }}$ (Mushy state)

$$
\gamma=\frac{\Delta H}{L}=1
$$

- $\quad$ If $\mathrm{T}>T_{\text {Liquidus }}$ (Liquid state)

$$
\gamma=\frac{\Delta H}{L}=1
$$

- The source terms $S_{i}$ and $S_{h}$ are given by:

$$
\begin{gathered}
S_{i}=-A(\gamma) u_{i} \frac{C(1-\gamma)^{2}}{\gamma^{3}+\varepsilon} u_{i} \\
S_{h}=\rho L \frac{\partial \gamma}{\partial t}
\end{gathered}
$$

Where $A(\gamma)$ is defined as the "porosity function" which governs the momentum equation based on Carman-Kozeny relationship for flow in porous media. The function reduces the velocities gradually from a finite value of 1 in fully liquid to 0 in fully solid state within the computational cells involving phase change. The epsilon $\varepsilon=0.001$ infinity avoidance constant due to division by zero and $\mathrm{C}$ is a constant reflecting the morphology of the melting front where $\mathrm{C}=10^{5}$.

Boussinesq approximation was adopted to calculate the change in PCM density as a function of temperature in the liquid density given by:

$$
\rho=\rho_{0}\left[1-\beta\left(T-T_{m}\right)\right]
$$

And the relationship of buoyancy forces in the momentum equation is given by:

$$
-\rho g=\rho_{0} g\left[\beta\left(T-T_{m}\right)-1\right]
$$

where $\rho_{0}$ is the reference density at melting temperature $T_{m}$ and $\beta$ is the thermal expansion.

The above equations (Eq. (1), (2) and (3)) which govern such heat transfer are solved by using the implicit finite volume method of the commercial code fluent 6.3.26.

A fixed grid space of $1 \mathrm{~mm}$ square for simulation with finite volumes and a variable time step with a minimum value of $0.01 \mathrm{~s}$ are used for all the simulations. The total number of grid is $132 \times 48$ for simulation (Fig. 1b).

\section{Results}

The results presented for the PV/PCM system, were obtained as mentioned in the above paragraph by using the commercial code Fluent. The balance for global convergence was taken as $10^{-6}$. The calculations were performed on I5, 3G RAM machine. The heat transfer coefficients on the front and rear surfaces are respectively 12.5 and $7.5 \mathrm{~W} \cdot \mathrm{m}^{-2} \cdot \mathrm{K}^{-1}$ and the insolation was $750 \mathrm{Wm}^{-2}$.

The governing equations of the problem are solved for several configurations of PV/PCM system. The numerical results thus obtained are presented for temperature and liquid fraction in Figs. 2-8. The computational procedure is validated against the experimental and numerical results of Huang et al. (2004). Then, we focus our attention on the effects fins on the cooling of the PV panel along the time. In order to find the best configuration.

\subsection{Validation}

The numerical model was validate against the experimental and numerical data of Huang et al. (2004) for the temperature (Fig. 2 and Fig. 3) during the $50^{\text {th }}$ minute. A good agreement was achieved, as illustrated in Fig. 2, between our results and the results of Huang et al. (2004) for temperature contours inside the PV/PCM system. The same behavior is observed during the $100^{\text {th }}$ minute for the temperature contours (not shown here). 


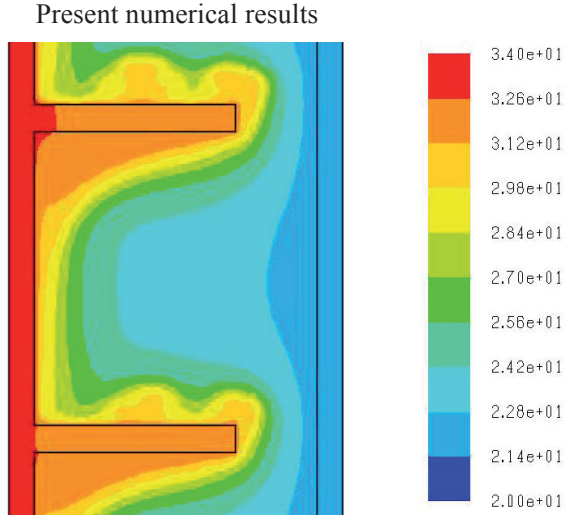

Experimental of Huang, 2004

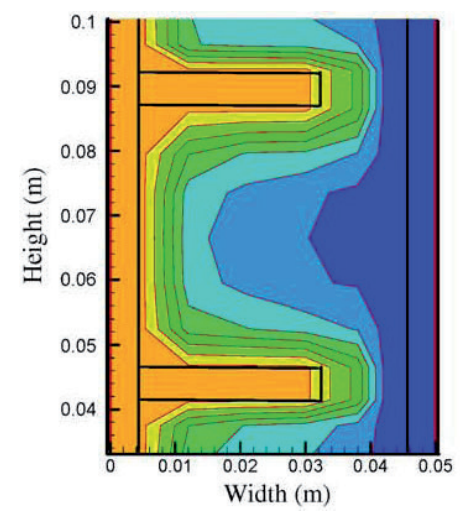

Fig. 2 Comparison between the temperature contours predicted numerically and the measured temperature contours during the $50^{\text {th }}$ minute.

Further validation has been performed by comparing the local temperature at two different positions, the first one is located in the front of the PV panel and the second one is inside the PCM along the time evolution between the present work and that of Huang. Again, the comparison strikes good agreement between both results as displayed in Fig. 3. These validations boost the confidence in our numerical code to carry on with the above stated objectives of the current investigation.

\subsection{Effect of inner fins}

A parametric study has been carried out to determine the influence of the length of internal fins inside the PV-PCM system. The influence of this length has been examined for the values $0,5 \mathrm{~mm}, 10 \mathrm{~mm}, 15 \mathrm{~mm}, 20 \mathrm{~mm}, 25 \mathrm{~mm}, 30 \mathrm{~mm}, 35 \mathrm{~mm}$ and $40 \mathrm{~mm}$, respectively. All of these cases have been computed during 250 minutes.

For the configuration without inner fins $(\mathrm{L}=0 \mathrm{~mm})$, we observe the formation of a boundary layer (see Fig. 4a, b), this one is extended along the vertical direction, it is slightly thinner at the bottom of the PV-PCM system and of large thickness at top of the system. The natural convection which develops along time generates this upward boundary layer, following the upward flow of the molten PCM particles that are slight (under the effect of heat exchange) compared to the particles of PCM less heated that tend to move down to take their places. For this configuration, we notice that the distribution of the temperature is not suitable to ensure good and homogenous cooling of the photovoltaic panel, as we observe from Fig. 2 that the bottom of the panel is cooled better than the top.

(a)

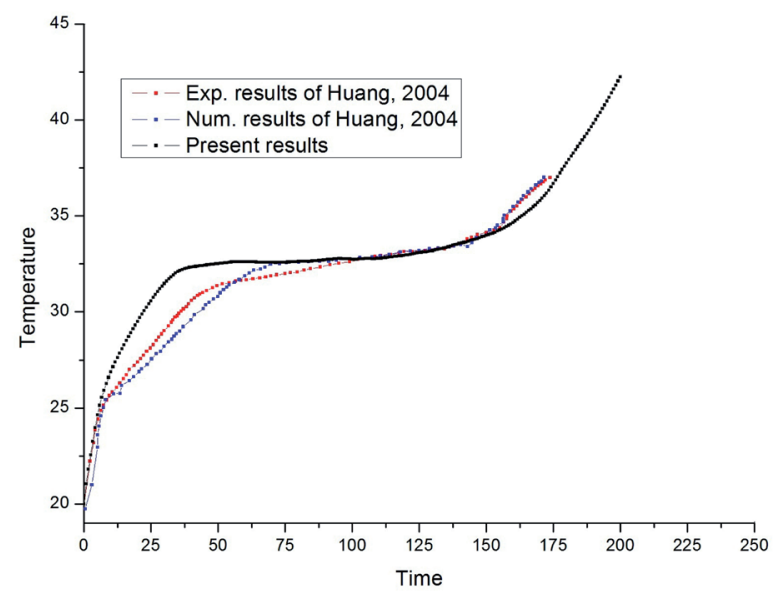

(b)

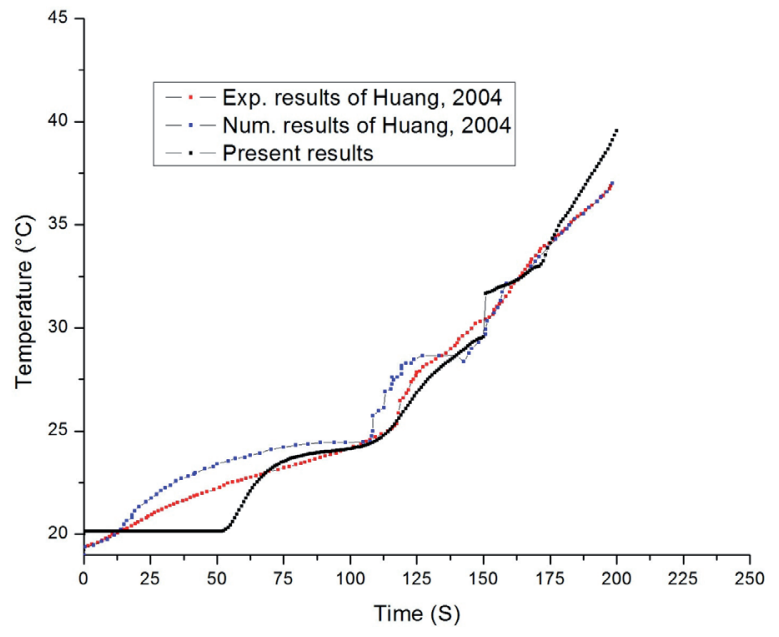

Fig. 3 Comparison between the temperatures predicted by the present 2D model and the data of Huang, 2004 at : a) the front (point Pf), and b) the inside of the PCM (Point Pint)

To remedy this problem, we will use the inner fins, to evenly distribute the heat load in the PCM, which is submitted to the photovoltaic panel by the solar radiation. It could be interesting to find the optimal length for proper cooling of the panel, doing this several inner fins of different lengths was been investigated : $\mathrm{L}=5 \mathrm{~mm} ; 10 \mathrm{~mm} ; 15 \mathrm{~mm} ; 20 \mathrm{~mm} ; 25 \mathrm{~mm}$; $30 \mathrm{~mm}, 35 \mathrm{~mm}$ and $40 \mathrm{~mm}$. Figure 5 shows the distribution of the isothermal contours for the cases under investigation at the $50^{\text {th }}$ minute. It is clearly noticed that for all configurations, the boundary layer is divided in three cells, which are significantly smaller compared to the case without inner fins. These last three cells are practically of the same size and guarantee a better distribution of the heat load in the PCM. We remark also that at the $50^{\text {th }}$ minute the configurations of $\mathrm{L}=25,30$ and $35 \mathrm{~mm}$ allow 
(a) Isotherms

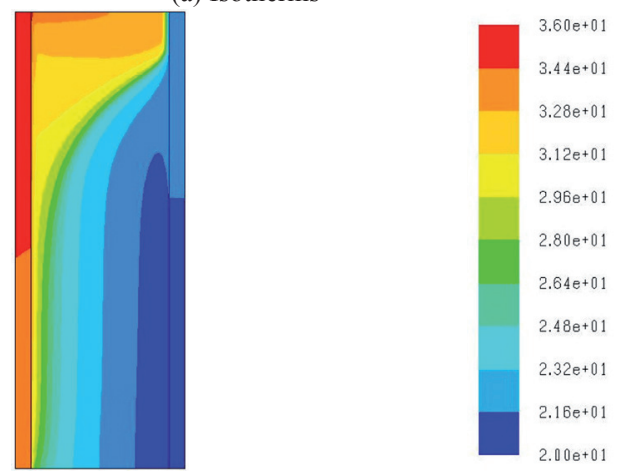

(b) Fraction liquid
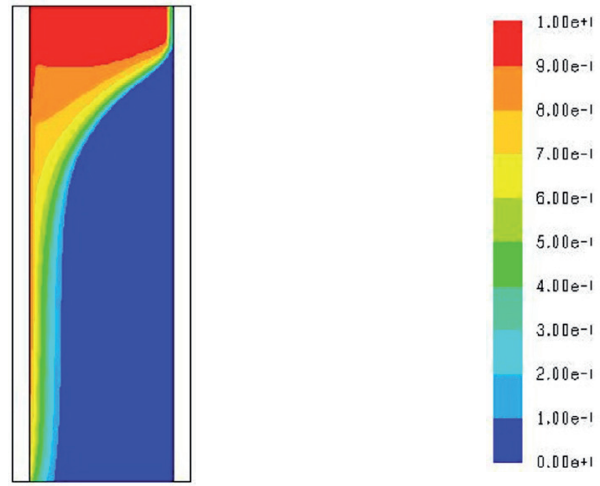

Fig. 4 Isotherms and fraction liquid fields in the SP/PCM system at the $50^{\text {th }}$ minute for the case without fins $(\mathrm{L}=0 \mathrm{~mm})$. better cooling of the PV panel. Concerning the case $\mathrm{L}=40 \mathrm{~mm}$, where the PV-PCM system is subdivided into three compartments (the inner fins are extended and bonded to the rear plate) the solar panel is less cooled in comparison with the other cases $(\mathrm{L}=35 \mathrm{~mm} 30 \mathrm{~mm} 25 \mathrm{~mm}$ ).

This is confirmed in Fig. 6, which shows the temporal evolution of the temperature of PV panel and of the PCM in a middle point along 250 minutes. It is clear that the three configurations ( $\mathrm{L}=25,30$ and 35$)$ allow for a better cooling of the $\mathrm{PV}$ panel, where the maximum temperature $\left(55^{\circ} \mathrm{C}\right)$ is reached at the $250^{\text {th }}$ minute. On the other hand, according to the same figure the case $\mathrm{L}=40 \mathrm{~mm}$ allows a better cooling from the $176^{\text {th }}$ minute.

In this investigation, we have tried to study also the effect of the inner fin incorporated on the back of the PV-PCM system (see Fig. 7), with back fin's length equal to "R". From the Fig. 7 which shows the temperature distribution for the configurations ( $\mathrm{L}=30 \mathrm{~mm}, \mathrm{R}=5 \mathrm{~mm}$ ) we notice practically no change on the behavior of isotherm contours compared to the configuration without back's fin $(\mathrm{L}=30)$ previously studied. Concerning the time history of the temperature displayed in Fig. 8, we remark that the back's inner fin is not suitable for the cooling the PVPCM system, in contrast it helps to increase the temperature of the PV panel and of the PCM.
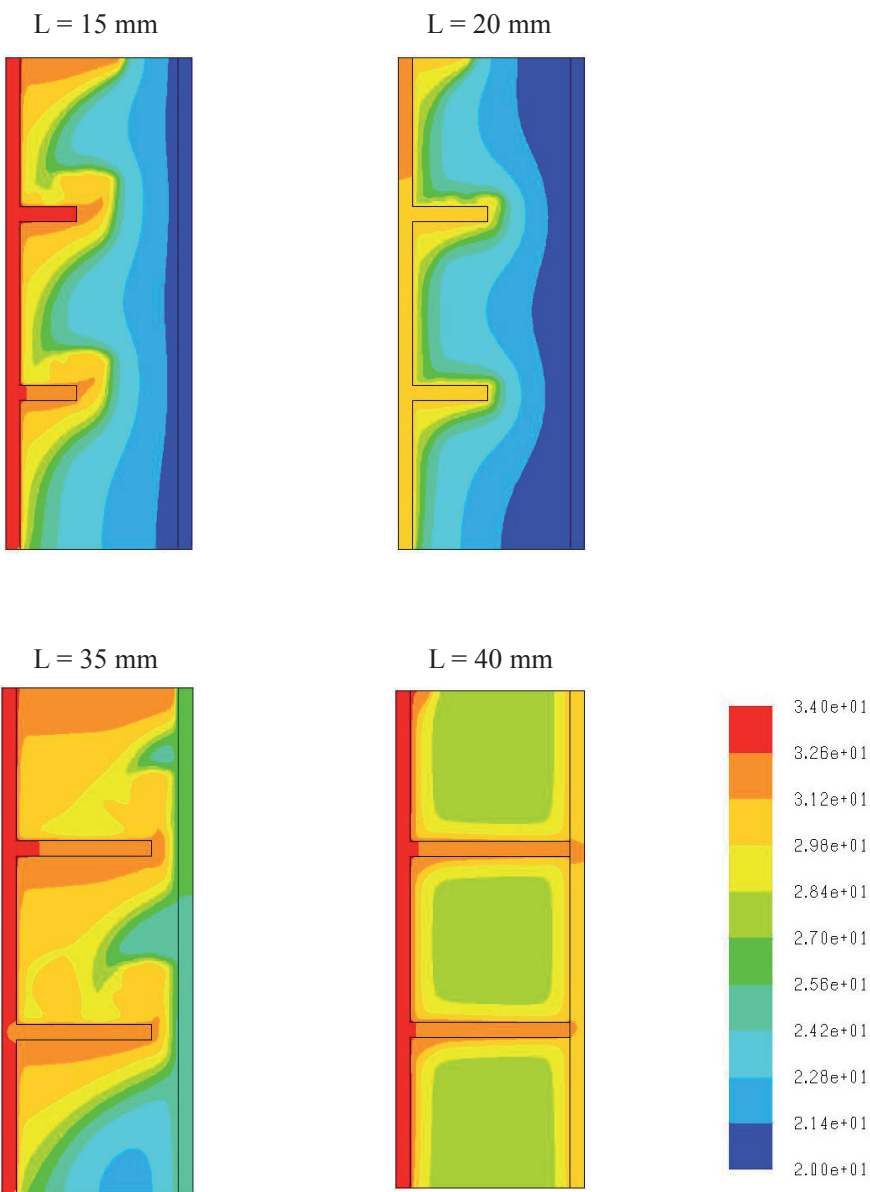

Fig. 5 The isotherm contours for different configurations of the PV/PCM system at the $50^{\text {th }}$ minute. 
(a)

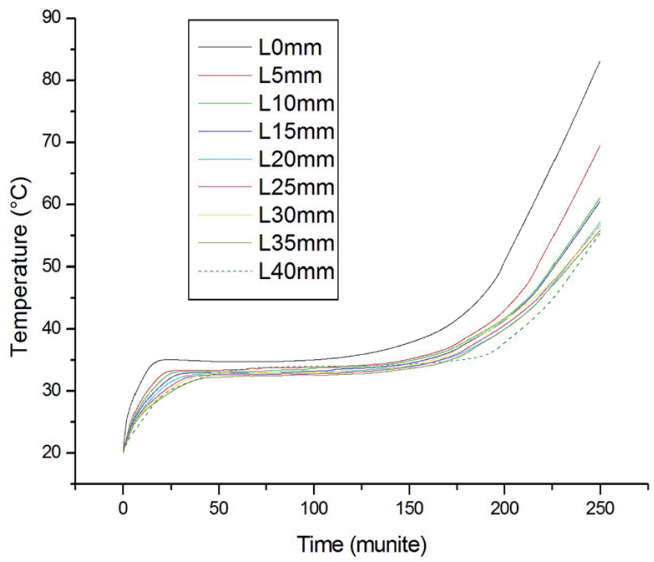

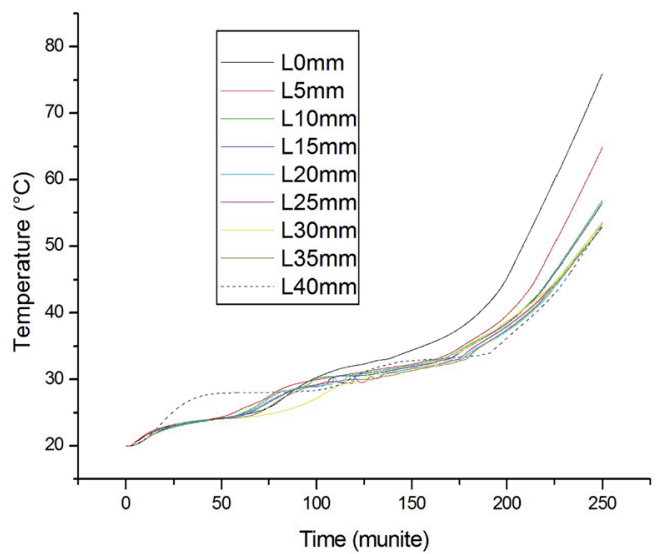

(b)

Fig. 6 The evolution of the Temperature along the time for different configurations at two locations: a) Front Point and b) Internal Point.

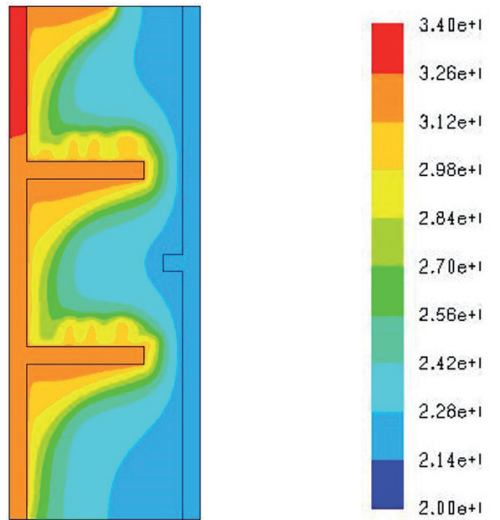

Fig. 7 The isotherm contours for the configuration of rear fin $(\mathrm{L}=30 \mathrm{~mm}$ and $\mathrm{R}=5 \mathrm{~mm})$.

(a)

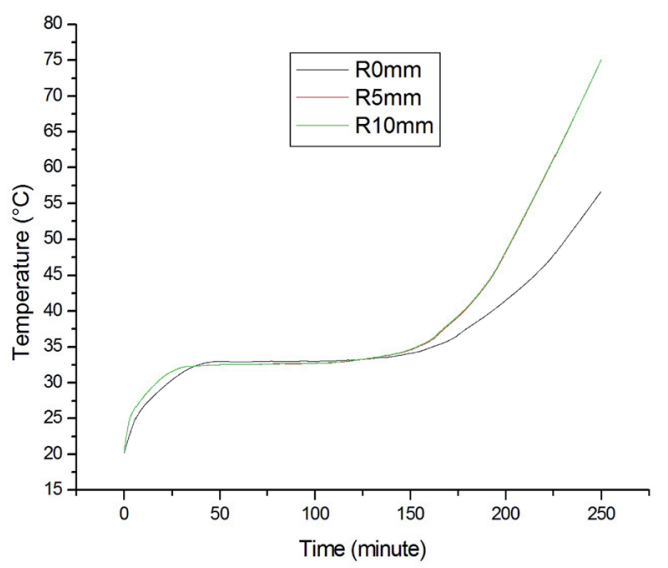

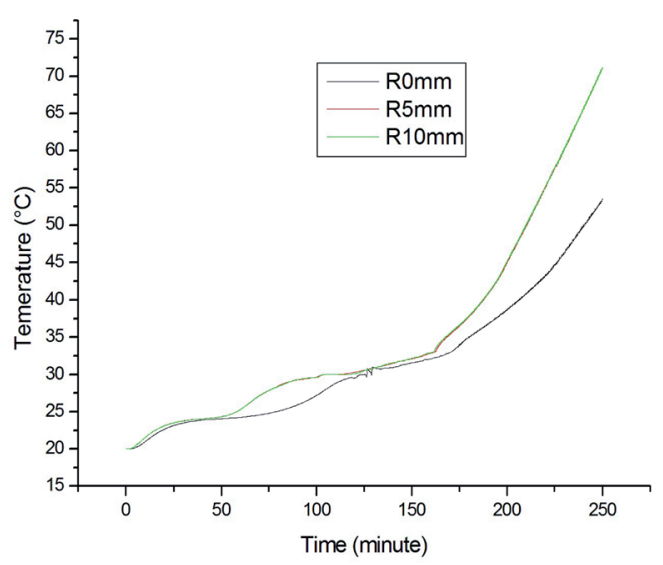

(b)

Fig. 8 The effect of the length of the rear fin on the time evolution of the Temperature at two locations: a) Front Point and b) Intern Point

\section{Conclusion}

As well known the temperature of the PV cell is one of the main important parameters that affect the energy performance of the PV panel. In this investigation, we tried to maintain the PV's temperature at a low value by incorporating a solid-liquid PCM and inner fins. The PCM 'RT25' chosen has a phase change similar to the PV characterising temperature of $25^{\circ} \mathrm{C}$. The aim of this work is to investigate numerically the melting behaviors and performance by using inner fins of different lengths in a rectangular encapsulation. Doing this, the
Commercial CFD software (Fluent 6.3) has been used to solve the conservation equations for mass, momentum and energy.

A good agreement was obtained between the present numerical results and those of the literature for the case $(\mathrm{L}=30 \mathrm{~mm})$ for both the isotherm contours and time evolution of the temperature.

The obtained results show that the inner fins of the front regulate the distribution of the temperature, by dividing the thermal boundary layer in three cells of medium size. It is interesting to confirm that these fins reduce significantly the increase 
of the temperature compared to the case configuration without inner fins. Furthermore, the configurations of $\mathrm{L}=25,30$ and $35 \mathrm{~mm}$ allow better cooling of the PV panel.

On the other hand, the back inner fin used in this investigation reduces dramatically the performance of the PV-PCM system for cooling the panel. Thus, it should be necessarily to use a smooth back for good cooling.

\section{References}

[1] Ingersoll, J. G. "Simplified calculation of solar cell temperatures in terrestrial photovoltaic arrays." ASME Journal of Solar Energy Engineering. 108(2), pp. 95-101. 1986. DOI: 10.1115/1.3268087

[2] Sala, G. "Chp. 8: Cooling of solar cells." In: Cells and optics for photovoltaic concentration. (Luque, A. (ed.)), pp. 239-267. Adam Hilger, Bristol, 1989.

[3] Horne, W. E. "Solar energy system." Patent US5269851, USA, 1993.

[4] Chaniotakis, E. "Modelling and Analysis of Water Cooled Photovoltaics." MSc Thesis, Department of Mechanical Engineering, University of Strathclyde, Glasgow, Scotland, 2001. URL: http://www.esru.strath. ac.uk/Documents/MSc_2001/efstratios_chaniotakis.pdf

[5] Royne, A. "Cooling devices for densely packed, high concentration PV arrays." MSc Thesis, University of Sydney, Sydney, Australia, 2005. URL: http://folk.uio.no/anjaroy/PVCooling.pdf
[6] Huang, M. J., Eames, P. C., Norton, B. "Thermal regulation of buildingintegrated photovoltaics using phase change materials." International Journal of Heat and Mass Transfer. 47, pp. 2715-2733. 2004.

DOI: 10.1016/j.ijheatmasstransfer.2003.11.015

[7] Huang, M. J., Eames P. C., Norton, B. "Phase change materials for limiting temperature rise in building integrated photovoltaics." Solar Energy. 80(9), pp. 1121-1130. 2006. DOI: 10.1016/j.solener.2005.10.006

[8] Ahmad, H. "Phase Change Materials for Thermal Regulation of Building Integrated Photovoltaics." $\mathrm{PhD}$ thesis, Dublin Institute of Technology, Dublin, Ireland. 2010. URL: http://arrow.dit.ie/cgi/viewcontent. cgi? article $=1035 \&$ context $=$ engdoc

[9] Huang, M. J., Eames, P. C., Norton, B. "Comparison of Predictions Made Using a New 3D Phase Change Material Thermal Control Model with Experimental Measurements and Predictions Made Using a Validated 2D Model." Heat Transfer Engineering. 28(1), pp. 31-37. 2007. DOI: 10.1080/01457630600985634

[10] Anon, RUBITHERM data sheet, Co. RUBITHERM GmbH, Hamburg, Germany. 2000.

[11] Hale, D.V., Hoover, M. J., O’Neil, M. J. "Phase Change Materials Handbook." NASA CR 61363. 1975.

[12] Rohsenow, W. M., Hartnett, J. P., Cho, Y. I. "Handbook of Heat Transfer." 3rd ed., McGraw-Hill, New York. 1998. 